\title{
intuitio
}

\section{INTERPRETAÇÕES BOECIANAS SOBRE INFERÊNCIAS TÓPICAS E ALGUMAS CONSIDERAÇÕES MEREOLÓGICAS'}

BOETHIAN INTERPRETATIONS: ON TOPICAL INFERENCES AND MEDIEVAL MEREOLOGY

Resumo: Pode-se ver na abordagem da mereologia medieval uma conexão bastante forte entre a metafísica e a lógica. Questões ontológicas acerca de termos comumente utilizados em tratados lógicos e consideradas como questões lógicas não eram incomuns. Assim, as discussões mereológicas, surgem com frequência, em textos medievais, em meio a questionamentos lógicos e em textos mais claramente ligados a essa vertente. É o caso da mereologia ligada aos tópicos, em particular na interpretação boeciana desses. Da mesma forma que com o problema dos universais, o esforço dedicado a solucionar problemas mereológicos está entrelaçado às bases das inferências tópicas bem como com seu uso. Pretendemos, através desse texto, realçar a conexão do trabalho de Boécio enquanto lógico com as questões metafísicas que surgem do estudo do todo e suas partes. Acreditamos que a interpretação boeciana deve ser considerada neste aspecto, em primazia de outras, por sua influência lógica até o final do período medieval.

Palavras-chave: Argumentos Tópicos. Mereologia. Boécio. Lógica Medieval.

\footnotetext{
O presente trabalho foi realizado com apoio da Coordenação de Aperfeiçoamento de Pessoal de Nível Superior - Brasil (CAPES) - Código de Financiamento oo1.

2 Doutoranda, PPG-Filosofia UFPel - Bolsista CAPES. http://orcid.org/0000-0003-1206-3722. E-mail: luanadacruz@ymail.com
} 


\begin{abstract}
One can see in the medieval approach to mereology a strong connection between metaphysics and logic. Ontological questions about the terms commonly used in logical treatises and questions were the usual methodology. Thus, the mereological discussions, in medieval texts, often arised amid logical arguments and texts more clearly linked to this line of reasoning. This is the case of meraology related to the Topics, in particular in the Boethian interpretation of these. Like with the problem of universals, the effort to achieve mereologic solutions was intertwined with the bases of Topical Inferences. Through this paper, we intend to emphasize the connection of Boethius' work as a logician with the metaphysical questions that arised from the study of the whole and its parts. We believe that the Boethian interpretation of this subject should be considered, in precedence of others, by its logical influence until the end of the medieval period.
\end{abstract} Keywords: Topical Arguments. Mereology. Boethius. Medieval Logic.

\title{
Introdução
}

Por mereologia entende-se um campo da metafísica que se preocupa com a relação entre o todo e suas partes, bem como a própria existência de um todo e suas partes, tendo sido discutido desde a antiguidade até a contemporaneidade.

A mereologia não é uma disciplina filosófica inventada no período contemporâneo. Enquanto área de investigação é possível dizer que discussões mereológicas são tão antigas quanto à própria filosofia, estando presentes pelo menos desde o desenvolvimento do atomismo na filosofia pré-socrática. Porém não há dúvidas que apenas a partir da obra de Lesniewski é que este ramo da metafísica obteve um tratamento sofisticado, à luz da lógica formal desenvolvida por Frege e Russell, entre outros ${ }^{3}$.

3 NUNES, R. O. Poblemas de Mereologia: O que é um todo? In: Revista do Seminário dos Alunos do PPGLM/UFRJ 
No período medieval, em particular, encontramos uma rica tradição mereológica, mesmo que, dada a tênue divisão entre a lógica e as demais disciplinas filosóficas como a ontologia, a maioria de suas discussões tenham acontecido como argumentos dialéticos. Ainda que as discussões medievais não sejam tão refinadas quanto àquelas oferecidas pela lógica contemporânea, a mereologia medieval trata, contudo, de questões tanto metafísicas quanto de lógica, como podemos notar em grande parte das abordagens do Problema dos Universais.

Mesmo que a ideia de fazer parte de algo seja por si só bastante complicada em seus desdobramentos filosóficos, durante o medievo há as considerações de que fazer parte de um todo deve ser diferenciado de uma espécie fazer parte de um gênero, pois não é o caso que todo e qualquer autor assuma que gênero e todo são termos intercambiáveis. Percebemos essa diferenciação, principalmente, no tratamento dos argumentos tópicos e, em particular, da interpretação boeciana desses, que influenciou a lógica medieval até o final do período. A concepção de lógica que Boécio segue, apega-se principalmente à teoria aristotélica sem, no entanto, comprometer-se com a demonstração de argumentos da forma como esperaríamos ao tratarmos de silogismos, pois a harmonização que o autor parece propor tem como base a argumentação tópica. Boécio assume plausibilidade, em certo sentido, como equivalente para validade, aceitando o aparentemente válido e verdadeiro como cogente, se $o$ argumento oferecido for convincente.

Boécio entende um tópico como o locus do argumento. Essa definição está enraizada em sua interpretação de como uma Differentia ${ }^{4}$ ou proposição máxima pode levar alguém a encontrar um argumento. De modo geral, as inferências tópicas servem ao propósito dialético de responder questões. Dessa forma, ainda que se saiba o assunto sobre o qual o argumento versa, é preciso que se encontre o termo médio cor-

\footnotetext{
4 Utilizaremos a distinção proposta por STUMP, E. entre maiúsculas e minúsculas para distinguir differentia (predicável) e Differentia de um argumento tópico.
} 
reto, o que se dá através da Differentia ou da proposição máxima. Para Boécio tais coisas não são intercambiáveis, sendo que ele dá à Differentia um papel de maior importância na busca e julgamento de argumentos tópicos. Cabe apontar, no entanto, que ambas deveriam ser capazes de delimitar o tema do argumento em questão.

Um argumento tópico, buscando oferecer o lugar do termo médio para a construção de um silogismo, se este for ao menos plausível, estabelece uma série de regras a partir das quais tal busca e construção devem ser feitas. A procura por uma proposição máxima ou Differentia se dá de acordo com certas regras e tais regras consideram tanto a divisão entre o todo e as partes quanto a separação entre o gênero e a espécie. A plausibilidade de um argumento tópico é o que garante o cumprimento da função de uma inferência tópica, de modo que a discussão mereológica que encontramos ligada aos tópicos está na base da formulação desse tipo de inferência.

Desde o início, os melhores filósofos medievais estavam conscientes das sutilezas da linguagem comum. Em particular, eles estavam atentos à função distributiva do termo adjetivo "todo" (totus / tota / totum). Isto é, que o termo "totus" pode agir como um quantificador universal e, portanto, a frase "totus $x$ " pode significar "todas as partes de $x$ consideradas juntas" ou "todo o x"5 (ARLIG, [2015], tradução nossa).

Ao considerar as categorias aplicáveis ao pensamento, Boécio recorre a Aristóteles e a uma leitura aristotélica através de Porfírio. Enquanto Aristóteles dá ênfase à divisão das categorias, o foco de Porfírio tende a ser na subdivisão dos chamados predicáveis, já assumindo as catego-

\footnotetext{
5 AR original: From the beginning, the best medieval philosophers are aware of the subtleties of ordinary language. In particular, they are mindful of the distributive function of the adjectival ttrm "whole" (totus/tota/totum). That is, the term "totus" can act like a universal quantifier and, hence, the phrase "totus $x$ " can mean "all the parts of x taken together" or "the entire $x$ ".
} 
rias de predicados como algo anterior e conhecido. As dez categorias ${ }^{6}$ (substância, quantidade, qualidade, relação, lugar, tempo, situação, ação, paixão, hábito) são essenciais à predicação, em particular, porque “(...) cada [categoria] é um gênero de muitas coisas, mas não é, ela mesma, uma espécie de coisa alguma"7 (STUMP, 1978, p. 237, tradução nossa). Essa abordagem estaria de acordo com a proposta boeciana de que existem modos de cognição de acordo com níveis de alcance mental e de conhecimento possíveis para cada nível. A fim de compreender o que se pode dizer de algo, de um ponto de vista mereológico enquanto associado às inferências tópicas, é preciso entender as dez categorias aristotélicas e tal compreensão se dá através dos predicáveis expostos conforme a interpretação boeciana dos tópicos.

\section{Os argumentos tópicos}

Considerando a cronologia das obras de Boécio estabelecida por $\mathrm{L}$. M. De Rijk ${ }^{8}$, seus tratados acerca dos tópicos são seus últimos trabalhos anteriores à Consolação da Filosofia e, conforme aponta Stump, parece ser o caso que Boécio pretendia sugerir que a Teoria do Silogismo e a Teoria dos Tópicos fossem mescladas, de modo a auxiliar na busca filosófica pela verdade bem como na argumentação dialética. Tais tratados deveriam tornar a descoberta de argumentos mais facilmente ao descobri-los através de proposições colocadas em dúvida, de modo que se obtivesse uma proposição máxima ou aquilo que Aristóteles chama de princípio e que Boécio entende por uma generalização universal autoevidente que oferece força ao argumento da mesma forma como uma Differentia. Se a demonstra-

\footnotetext{
6 Não consideraremos aqui as complicações das Cctegorias aristotélicas. Para uma discussão aprofundada, ver ZINGANO, M. "A Categorias de Aristóteles e a doutrina dos traços do ser". In: dois pontos - Temas de Filosofia Antiga, 2013., . 225 -24.

7 ST original: (...) each is a genus to many other things but is itself not a species of anything.

8 Ver DeeRijk (1964).IJ
} 
ção que passou a ser conhecida como dialética ${ }^{9}$ deve ocorrer através de argumentos tópicos, uma vez que tais argumentos servem para responder perguntas, especificamente aquelas advindas da ciência do discurso, das teorias da natureza e das teorias morais, de modo que o autor considera que tal forma de argumentação, "aponta, de certa forma, o caminho da

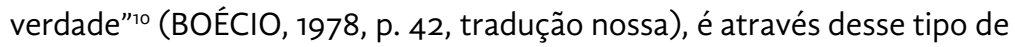
inferência que se pode encontrar a definição da própria virtude, pois o conceito filosófico, uma vez colocado em dúvida, pode ter a sua definição encontrada através do raciocínio tópico. As proposições máximas e as Differentiae são consideradas parte de um tópico para Boécio, sendo que a primeira poderia ser considerada como tradicional. O interesse de Boécio não se limita à tradição aristotélica"1 nem, tampouco, sua interpretação.

Boécio pensa que proposições máximas são o que Aristóteles chama Tópicos. Quando Aristóteles dá um Tópico, ele, geralmente, apresenta tanto uma estratégia para argumentação quanto um princípio. Alguns intérpretes dos tópicos de Aristóteles, como Teofrasto, consideram apenas os princípios como Tópicos; outros, como Alexandre de Afrodísia, pensam que Aristóteles quer dizer tanto a estratégia quanto o princípio por Tópicos; e não é impossível que Aristóteles tenha entendido a estratégia por si só como o Tópico real. Ao sugerir

\footnotetext{
9 Cabe ressaltar que reconhecemos a distinção entre Argumentos Tópicos Retóricos e Argumentos Tópicos Dialéticos, mas tal distinção não nos preocupa aqui. Quando nos referimos à dialética, de modo geral, não nos referimos ao tipo de argumento, mas ao método da lógica medieval conforme encontrado no Trivium.

10 original: (...) it points out in a certain way the path of truth.

1 Ainda que Boécio tenha, conforme aponta Liebeschütz, estabelecido o vocabulário da abstração do medievo, em particular da escolástica, e que esse vocabulário era, em grande parte, aristotélico, isso é notado pelo fato de que "a razão mais forte para remontar a origem da Escolástica a Boécio é derivada de sua aplicação da terminologia aristotélica na definição da doutrina trinitária" LIEBESCHÜTZ, H. "Boethius and the Legacy of Antiquity". In: ARMSTRONG, A. H. (ed). The Cambridge History of Later Greek and Early Medieval Philosophy, 1967, p. 543. Do original: The strongest reason for tracing the origino $f$ scholasticism back to Boethius is derived from his application of Aristotelian terminology to the definition of trinitarian doctrine. Ibidem, p. 543.
} 
que as proposições máximas são os Tópicos aristotélicos, Boécio está, na verdade, se alinhando com a interpretação de Teofrasto'² (STUMP, 1978, p. 180, tradução nossa).

É na terminologia aristotélica que o filósofo frequentemente se apoia ao discutir questões para além da lógica ou interpretações lógicas advindas de outras escolas de pensamento. Ainda que não seja o caso que Boécio se diga aristotélico, pode-se perceber que é em Aristóteles que ele encontra clareza no tratamento de questões que considera importantes, tal como exemplificado em sua linguagem aristotélica nos textos da Opuscula Sacra. Desse modo, mesmo quando o filósofo grego não chega às mesmas conclusões que Boécio favorece, há certa relutância em descartar seus raciocínios e parece ser preferível a Boécio justificar o que poderia ter levado Aristóteles ao erro e como seu pensamento não sofre nenhum demérito com tal coisa.

No entanto, Boécio afasta-se de Aristóteles ao tornar os tópicos dependentes de uma leitura psicológica na qual a produção de crença é logicamente preferível à demonstração necessária. Ainda que ambos concordem que, a fim de convencer em uma argumentação, inferências tópicas deveriam ser utilizadas, no caso de Boécio tais inferências são suficientes para que qualquer um que não se especialize no conteúdo discutido possa ser convencido. Isso se dá uma vez que a proposição máxima seja entendida, aqui, como uma verdade autoevidente geral da qual qualquer verdade secundária pode ser derivada e provada. Dessa forma, conforme aponta Stump (1978, p. 187, tradução nossa):

\footnotetext{
12 original: Boethius thinks maximal propositions are what Aristotle calls Topics. When Aristotle gives a Topic, he generally presents both a strategy for argumentation and a principle. Some interpreters of Aristotle's Topics, such as Theophrastus, consider only the principles to be Topics; others, such Alexander of Aphrodisias, think Aristotle means both the strategy and the principle to be Topics; and it is not impossible that Aristotle understood the strategies alone to be the real Topics. In suggesting that maximal propositionsare Aristotle's Topics, Boethius is in effect allying himself with Theophrastus's interpretation.
} 
Proposições máximas funcionam na argumentação como garantidores de validade ou cogência. Nos argumentos predicativos de Boécio baseados em proposições indefinidas, elas são premissas gerais essenciais para a validade da argumentação; em argumentos hipotéticos, elas validam a passagem do antecedente para o consequente - isto é, elas verificam a premissa condicional'3.

As Differentiae identificam o conteúdo da proposição máxima e, portanto, do argumento em questão. Assim sendo, é a Differentia e não a proposição máxima que descobre argumentos, de modo que "(a) Differentia não providencia um termo médio específico, ao invés disso, ela sugere o tipo de termo que poderia ser o termo médio"14 (STUMP, 1978, p 197, tradução nossa). Uma vez que se conheça o conteúdo do argumento, pode-se encontrar o termo médio adequado bem como a proposição máxima capaz de oferecer força para a ele. Dessa forma, a interpretação de Boécio depende dos tópicos de Aristóteles, dos tópicos de Cícero e dos predicáveis de Porfírio, mas não se restringe apenas à interpretação oferecida por qualquer um desses filósofos. Embora não tenha uma teoria própria de inferências tópicas, o que ele propõe "parece ser a única representação sobrevivente de um desenvolvimento significativo na história da dialética”15 (STUMP, 1978, p. 214, tradução nossa), segundo a qual, um tópico é tanto uma estratégia quanto uma Differentia, capaz de encontrar o termo médio e a proposição máxima que dá força ao argumento formado a partir de tal termo.

A preocupação de Boécio com a predicação e o modo como esta afeta as proposições máximas e Differentiae já aponta para a sua tentativa de

\footnotetext{
13 Do original: So maximal propositions function in argumentation as guarantors of validity or soundness. In Boethius's predicative arguments based on indefinite propositions, they are general premises essential to the validity of the argument; in hypothetical arguments, they validate the passage from antecedent to consequent in the conditional - that is, they verify the conditional premise.

14 Do original: (the) Differentia does not work by providing a particular intermediate term; instead it suggests the sort of term that could serve as intermediate.

15 ST original:(...) seems to be the sole surviving representative of a significant development in the history of dialetic.
} 
harmonizar os tópicos como uma parte lógica que pudesse buscar o que ele chama de caminho da verdade. Dado que proposições são concebidas no intelecto e obtêm sua força e características tanto da imaginação quanto da verificação empírica, pode-se considerar que Boécio aceitaria dois tipos de pensamentos ${ }^{16}$. Um primeiro tipo de pensamento, aquele que corresponderia às coisas como elas são no mundo, não derivaria das próprias coisas, mas, sim, encontraria força em ser confirmado no mundo, relativizando a concepção de mundo a partir do sujeito.

Ele afirma que (iv) imagens mentais e (v) pensamentos diferem com base em uma passagem citada na obra De anima de Aristóteles, na qual Aristóteles sugere que uma combinação de pensamentos simples é uma verdade ou uma falsidade enquanto uma combinação da imagens mentais não é. Além disso, ele diz que imagens mentais são algo confuso e que o intelecto explica (explicat) as partes confusas de tais imagens mentais. Ele compara as imagens mentais com esboços em preto e branco que intelecto colore. Em outras palavras, imagens mentais são algo imperfeito, mas nomes e verbos significam algo perfeito. Dado que imagens mentais não são perfeitas, a alternativa restante do significado é o (v) pensamento. Assim, Boécio afirma que pensamentos são 'as afeccções da alma' que são significadas por palavras faladas, nomes e verbos: 'Assim, isto é a opinião correta de Aristóteles: Qualquer coisa é refletida (versantur) em verbos e nomes, significando nem sensações (sensus) nem imagens mentais (imaginationes), mas sim, significando apenas (sola) a qualidade de pensamentos'17 (SUTO, 2012, p. 30, tradução nossa).

\footnotetext{
${ }_{16}$ Marenbon (2003) sugere que tal divisão seja identificada como pensamentos correspondentes (aqueles que correspondem a algo na realidade) e pensamentos não correspondentes (aqueles que existem apenas na mente). Adotaremos, aqui, tal nomenclatura. $V$

17 SU original: He claims that (iv) imaginations and ( $v$ ) thoughts differ on the basis of a passage quoted from Aristotle's De anima where Aristotle suggests that a combination of simple thoughts is truth or falsity while a combination of imaginations is not. Moreover, he says that the imagination is something confused and that the intellect explicates (explicat) the confused parts of the
} 
Um pensamento enquanto afecção da alma é, antes de tudo, uma proposição, mas tanto se considerarmos essas proposições como apenas linguísticas, quanto se as consideramos como coisas no mundo, o que estaria envolvido através de um dos pilares da argumentação tópica seria o Problema dos Universais. A classificação boeciana de pensamentos como correspondente ou não é uma verificação empírica de seu valor de verdade, que depende da resposta de Boécio ao problema dos universais ${ }^{18}$. Há em Boécio a preocupação daquilo que é individual, sendo que podemos, de modo geral, entender particular e individual como expressões da mesma coisa, ainda que, para fins sentenciais, possuam algumas diferenças. Essa abordagem torna-se mais clara com o tratamento dos modos de cognição que podemos encontrar na Consolação da Filosofia, segundo o qual, o nível abstração do intelecto define nossa capacidade de compreender a totalidade do mundo.

\subsection{Predicáveis}

As cinco subcategorias definidas por Porfírio, que ele chama de predicáveis, não são uma redução dos predicados aristotélicos a outra forma ou resumo dos mesmos, uma vez que "[n]enhuma dessas categorias é redutível ou subordinada às outras; nenhuma delas, quando consideradas juntas, fica sob qualquer outra categoria mais geral, mas tudo é subordinado a uma ou outra delas"19 (STUMP, 1978, p. 237, tradução nossa). Quanto aos

\footnotetext{
imagination. He compares the imagination to sketching in black and white and the intellect to painting in color. In other words, the imagination is something imperfect, but nouns and verbs signify something perfect. Given that the imagination is not perfect, the remaining alternative of the significate is ( $v$ ) thoughts. Hence, Boethius claims that thoughts are 'the affections of the soul' that are signified by spoken words, nouns and verbs: "Hence, this is Aristotle's correct opinion: Whatever are reflected upon (versantur) in verbs and nouns signify neither sensations (sensus) nor imaginations (imaginationes) but signify only (sola) the quality of thoughts".

18 No entanto, cabe apontar que ainda que a preocupação de Boécio acerca de particulares e universais seja importante, assim como seu trabalho acerca da divisão, mesmo relacionados à ideia central desse artigo, não são seu foco principal.

19 ST original: None of these categories is reductible to or subsumed under any of the others; none of them taken together fall under any other, more general category, but everything is subsumed under one or another of them.
} 
predicáveis aristotélicos, apenas três das classes de predicáveis porfirianos são os mesmos que aqueles encontrados em Boécio e, cabe ressaltar que, ainda que haja uma parte dos predicáveis em Porfírio que sejam utilizados por Aristóteles, a saber, definição, gênero, acidente e propriedade, entre estes, se nota uma diferença no tratamento das classificações. Vemos nos predicáveis porfirianos maior importância em gênero, acidente e propriedade, sendo que ele adiciona à lista espécie e differentia. O que acontece é que:

Aristóteles enfatiza quatro predicáveis: gênero, definição, propriedade e acidente; o Isagoge de Porfírio é dedicado a cinco: gênero, espécie, differentia, propriedade e acidente. Existem, assim, seis predicáveis ao todo; e, mesmo que Boécio considere os quatro predicáveis de Aristóteles em De topicis differentiis (ver 1177D1off.), ele frequentemente faz uso dos outros dois nesse tratado ${ }^{20}$ (STUMP, 1978, p. 248, tradução nossa).

Boécio recorre tanto às differentiae quanto à definição como parte de seus predicáveis, desenvolvendo uma forma de predicação que pressupõe tanto a interpretação neoplatônica do Organon quanto o texto original. Mesmo que Boécio recorra às interpretações de Porfírio, sua insistência em utilizar a metodologia aristotélica para tratar de tais questões reafirma seu comprometimento com o filósofo grego.

Enquanto a argumentação dialética é compreendida da mesma forma e ambos os autores assumem que há uma estratégia a ser aprendida para desenvolver a argumentação tópica dialética, Boécio se afasta de Aristóteles em quase todos os demais pontos.

Para Aristóteles, então, um Tópico é uma estratégia baseada em um princípio e, o método de Aristóteles para a descoberta

\footnotetext{
20 So original: Aistotle emphasizes four predicables: genus, definition, property, and accident; Porphyry's Isagoge is devoted to five: genus, species, differentiae, property, and accident. There are, then, six predicables in all; and through Boethius gives Aristotle's four as the predicables in De top. Diff. (see 1177D10FF.), he often makes use of the other two as well in this treatise.
} 
de argumentos consiste em conhecer a natureza de um predicável (tal qual gênero) bem como averiguar se seu oponente violou alguma regra acerca de tal predicável ${ }^{21}$ (STUMP, 1978, p. 206, tradução nossa).

A importância dos predicáveis se dá, na interpretação boeciana da argumentação tópica, como um modo de reconhecer a differentia e, consequentemente, o locus do argumento. Tanto as proposições máximas quanto as próprias Differentiae dependem do que se pode dizer de algo, ou seja, do que se pode predicar a algo. A partir disso, podemos encontrar o argumento em questão. A estrutura formal por si só, é incapaz de encontrar o tópico, mas, o conhecimento dos predicáveis associados com o conteúdo sobre o qual se argumenta faz com que o tópico aponte a estrutura correta e indique seu termo médio. Assim, as regras da argumentação, ainda que importantes, não são centrais ao desenvolvimento das inferências tópicas.

Em certos sentidos, um predicável pode ser considerado equivalente a outro, mas, no entanto, suas funções diferem em pontos essenciais. Assim, tal equivalência não é suficiente para dizer que um predicável é capaz de substituir completamente outro. Entendemos tanto gênero quanto definição como partes da essência da coisa, estando presentes necessariamente no sujeito cujo predicado cada um deles indica. Assim, gênero, enquanto predicável, pressuporia a existência de um todo que seria a essência de algo. Mesmo que seja tentador identificar esse todo com as categorias aristotélicas, o que estamos discutindo aqui passa a ser a essência do que existe, pois enquanto gênero e definição são por si só cada um, um todo enquanto predicáveis, são também partes de algo maior, de modo que sua existência ou a aceitação de sua existência resulta na defesa de algo que compreenda esses predicáveis

21 So original: For Aristotle, then, a Topic is a strategy based on a principle, and Aristotle's method for the discovery of arguments consists in knowing the nature of a predicable (such as genus) and checking to see whether one's opponent has violated some rule regarding it. 
como suas partes ${ }^{22}$. As partes de algo são consideradas como sendo capazes de dizer coisas sobre o seu todo, a ponto de que essa é considerada uma justificativa linguística no estudo de sentenças complexas e não complexas, “(...) porque o conhecimento da parte é muito útil para o conhecimento do todo (...)"23 (BURLEY, 1995, p. 15, 21, tradução nossa).

Predicados e, consequentemente, predicáveis podem, em particular na visão mereológica difundida no medievo, nos dizer algo sobre como o mundo realmente é. Dessa forma, sua classificação parece consideravelmente importante. Eles podem ser classificados de duas formas: 1) comum e geral ou 2) singular e individual. Nenhuma dessas classificações é, no entanto, exclusiva, pois sua classificação ocorre de forma hierárquica ${ }^{24}$, de modo que ambas as categorias são aplicáveis a qualquer predicável. Definição, differentia e gênero são classificados da mesma forma, independentes de serem ou não parte da essência do sujeito ou de se expressarem de forma igual ou maior que ele. Mais do que isso, sua classificação hierárquica é a mesma, a saber, primeiro geral e depois singular. A generalidade de um predicável não é suficiente para identificar o predicável em questão e faz com que sua identificação dependa de outros fatores, assim como acontece na tentativa de distinção de gênero e definição. É apenas através da atribuição de características particulares a cada um deles, em especial a fim de reconhecer differentia e gênero como itens distintos apesar de suas similaridades, que é possível utilizar os predicáveis de modo apropriado. Tais predicáveis podem ser diferenciados apenas em função de

\footnotetext{
22 A fim de diferenciá-los, apontamos que gênero é um predicável maior do que o seu sujeito, ou seja, gênero contém seu sujeito sem ser contido por ele, e que definição é um predicável igual ao seu sujeito, sendo, portanto, um predicável conversível e que pode ser predicado ao sujeito da mesma forma que o sujeito pode predicá-lo. Gênero, portanto aplica-se a outras coisas além do sujeito enquanto o mesmo não ocorre com definição, pois definição possui uma característica que é particular de predicáveis iguais ao sujeito de modo que gênero jamais poderia tornar-se um predicável conversível.

23 BU original: “(..) because a knowledge of the part is very helpful for knowing the whole (...).

24 Algo só pode ser predicado a um indivíduo de uma espécie por ser predicado dessa espécie se tal predicado for aplicável a tal espécie como gênero. Pode-se dizer que um homem $\mathrm{x}$ é mortal porque homens são mortais.
} 
sua predicação, pois tanto gênero quanto differentia ou definição são parte da essência do sujeito bem como são, também, algo comum e geral. Mais do que isso, differentia e gênero são ambos maiores que seu sujeito. Até o momento em que predicam algo, não há distinções suficientes para reconhecer, com certeza, um predicável ou outro. Todavia, apenas differentia predica características que o sujeito possui, no sentindo de tal característica ser algo que o sujeito tem e não que ele é. Definição e gênero, por outro lado, são predicados acerca daquilo que o sujeito é e predicam características de tal tipo. Dado que gênero e definição podem ser diferenciados por definição ser um predicado conversível, o fato de dividirem o modo de predicação não afeta a possibilidade de distingui-los.

Assim, differentia é aquilo que é maior do que o sujeito de modo que pode predicá-lo, mas não pode ser predicado por ele; é comum e geral antes de ser singular e individual; pertence à essência do sujeito e predica características que o sujeito tem. Gênero é aquilo que é maior do que o sujeito de modo que também pode predicá-lo, mas não pode ser predicado por ele; é comum e geral antes de ser singular e individual; pertence à essência do sujeito, mas predica características do que o sujeito é. Já definição, é aquilo que é igual ao sujeito, sendo um predicável conversível, enquanto parte de sua essência; é comum e geral antes de ser singular e individual e predica características do que o sujeito é. Apesar da possível distinção, Boécio considera que differentia e gênero podem ser intercambiáveis desde que se divida differentia corretamente, a fim de obter tal resultado. Isso acontece por ser a differentia um predicável redutível a um dos quatro predicáveis aristótelicos, uma vez que, em sua forma constitutiva, pode ser entendida como gênero e, em sua forma divisiva, como espécie.

Após os comentários de Boécio sobre as differentiae constitutiva e divisiva, ele diz que, apesar de algumas differentiae tomarem o lugar de gênero e algumas, assim, tomarem o lugar de espécie, todas as questões em que o predicável é 
uma differentia são equivalentes às perguntas em que gênero é predicado 25 (STUMP, 1978, p. 260, tradução nossa).

Através da divisão constitutiva/divisiva, differentia pode exercer as mesmas funções de gênero apesar de suas diferenças predicativas. Cabe ressaltar que, para Boécio uma differentia constitutiva em conjunto com um gênero é capaz de oferecer a definição de uma espécie enquanto uma differentia divisiva divide o gênero a fim de formar tal espécie. Ainda que elas sejam complementares, não é o caso que ambas sejam necessárias para o reconhecimento de um gênero ou espécie. Uma differentia constitutiva pode ser reconhecida por ser parte da definição de uma espécie enquanto que uma divisiva pode ser encontrada ao se analisar a divisão que origina tal espécie a partir de um gênero. Todavia, ainda que "(...) todas as differentiae constitutivas são suficientes para especificar apenas gênero sem especificar, também, espécie"26 (STUMP, 1978, p. 260, tradução nossa), Boécio deixa a desejar quanto a aplicação dessa distinção e as razões de querer fundamentá-la ${ }^{27}$.

Há que se considerar, também, que definição é um predicável anterior tanto a differentia quanto a gênero, ainda que não seja maior que seu sujeito. Assim, apesar das similaridades com ambos, differentia e gênero seriam partes da definição que, através das classificações obtidas até aqui, seriam a essência da qual o sujeito ou objeto faz parte quando é predicado. Recorrendo à concepção aristotélica, "uma definição, ele diz, é uma expressão significando a essência de algo, e uma definição consiste do gênero e da differentiae do que está sendo definido"28 (STUMP, 1978, p. 238, tradução

\footnotetext{
25 ST original:: fter Boethius's remarks about constitutive and divisive differentiae, he says that, though some differentiae take the place of genus and some then place of the species, all questions in which the predicable is a differentia are equivalent to questions in which genus is predicated.

${ }_{26}$ Tr original: (...) all constitutive differentiae are sufficient to specify only genus and not also a species. ST

27 Enquanto a fusão interpretativa de predicáveis a partir de Boécio tem grande influência, a divisão que ele propõe entre tipos de differentiae acaba por ser confusa e pouco utilizada.

${ }_{28}$ ST original:Tr...) a definition, he says, is an expression. Signifying the essence of something, and a definition consists of the genus and the differentiae of what is being defined.
} 
nossa). Assim, uma definição contém nela mesma tanto o gênero quanto a differentia daquilo que ela define, de modo que algo pode, também, ser definido através de seu gênero e differentia, pois a definição trata-se de um todo completo. Aqui, haveria espaço para questionar o tipo de todo, sua relação com as partes e se as relações lógicas entre os predicáveis são, de fato, suficientes para reconhecer definição como um todo.

\subsection{A mereologia dos Tópicos de Boécio}

Ainda que a maior parte da mereologia medieval tenha seu ápice em discussões acerca da divisão, encontramos no tratamento dos tópicos duas proposições máximas e Differentiae que merecem ser consideradas. Já em sua introdução da divisão de predicação e da divisão tópica, Boécio apresenta gênero e espécie como algo diferente de parte e todo. Assim como os predicáveis aristotélicos se seguem das espécies (que por sua vez se segue de gênero, que se seguem das categorias), as partes se seguem do todo. Não apenas isso, mas as partes se seguem do todo de modo similar ao que os efeitos se seguem das causas. Mais do que isso, um dos exemplos mais claros da construção de um tópico e que será utilizado novamente na Consolação da Filosofia, se dá através da Differentia "do todo".

(...) suponha que haja uma questão sobre se os assuntos humanos são regidos pela providência. Diremos: se o mundo é governado pela providência, e os homens são parte do mundo, então (igitur) os assuntos humanos são regidos pela providência. A questão tem a ver com acidente. O Tópico: o que serve para o todo também serve para a parte. O Tópico superior: do todo, isto é, da coisa completa que é composta de partes, e esse é o mundo, que é o todo relativo aos homens ${ }^{29}$ (BOÉCIO, 1978, [1188C, 25-32], Livro II, p. 51, tradução nossa)

29 BO original: (...) suppose there is a question whether human affairs are ruled by providence. We will say: if the world is ruled by providence, but men are part of the world, then (igitur) 
A partir dessa construção, podemos entender que o mundo, para Boécio, é o todo, desde que isso seja considerado do ponto de vista humano. Temos aqui, novamente, traços dos modos de cognição que ele apresentará mais claramente na obra Consolação da Filosofia. As coisas que existem e que constituem um todo dependem do sujeito que as percebe e, desse modo, para o homem, o mundo é o todo mesmo que para Deus, que conhece todas as coisas, o mundo é uma parte. É importante notar que Boécio utiliza duas Differentiae para o tópico "do todo", uma maior e uma menor. Isso se dá a fim de possibilitar a diferenciação entre o todo e suas partes e o gênero e suas espécies. Notamos isso ao considerar o argumento anterior:

O que é um todo como gênero geralmente fornece argumentos para perguntas dessa maneira. Por exemplo, se há uma pergunta se a justiça é vantajosa, produz-se o silogismo: toda virtude é vantajosa, a justiça é uma virtude; portanto, a justiça é vantajosa. A questão aqui é sobre acidente, isto é, se a vantagem é um acidente de justiça. O Tópico que é uma proposição máxima é o seguinte: o que está presente para o gênero está presente para a espécie. O Tópico superior é do todo, isto é, do gênero, a saber, a virtude, que é o gênero da justiça ${ }^{30}$ (BOÉCIO, 1978, [1188B-1188C, 14-24], Livro II, p. 51, tradução nossa).

Assim, ainda que gênero seja um tipo de divisão do todo, não é o mesmo que dividir o todo em partes. Algo pode ser dividido em partes, que são elas mesmos gêneros e, portanto, ser dividido em gêneros sem que nenhum deles seja um todo, exceto através da relativização do ponto de vista do sujeito. De

human affairs are ruled by providence. The question has to do with accident. The Topic: what suits the whole fits the part also. The highest Topic: from the whole, that is, from the complete thing which is made up of parts, and that is the world, which is the whole relative to men.

30 Bo originial: What is a whole as a genus often supplies arguments to questions in this way. For example, if there is a question whether justice is advantageous, one produces the syllogism: every virtue is advantageous, justice is a virtue; therefore, justice is advantageous. The question here is about accident, that is, whether advantage is an accident of justice. The Topic which is a maximal proposition is this: whatever is present to the genus is present to the species. The higher Topic of this is from the whole, that is, from the genus, namely, virtue, which is the genus of justice. 
forma similar, Boécio aborda os tópicos quanto às partes de duas maneiras, diferenciando àquelas que são espécies daquelas que são partes de um todo. No entanto, ele afirma que “(...) as partes de um gênero, e estas são espécies (...) as partes de algo completo, ou seja, de um todo cujas partes são as únicas devidamente chamadas 'partes'”31 (BOÉCIO, 1978, [1188C, 34-36], Livro II, p. 51, tradução nossa). Isso provavelmente ocorre porque os seres humanos apenas possuem uma visão completa do gênero, de modo que somente as espécies podem ser completamente compreendidas. Um todo disponível para o nível de cognição humana, é um todo que, para os seres humanos, poderia não existir. Os desenvolvimentos mereológicos que encontramos em Boécio ou a partir de suas interpretações parecem estar profundamente conectados a seus estudos lógicos, sendo, na maioria das vezes, fruto destes. Ainda que haja um aspecto principalmente epistemológico na ideia dos modos de cognição, este aspecto não parece ser o centro de sua argumentação e sim uma das consequências de suas interpretações lógicas.

\section{Considerações finais}

A lógica, como Boécio a concebe, não existe isolada como requisito para o estudo de filosofia e, sim, como o conjunto de regras que guia o próprio pensamento e que está intimamente conectado às demais disciplinas filosóficas. Nesse sentido, não é surpreendente que suas principais contribuições mereológicas estejam entrelaçadas com problemas lógicos, pois Boécio considerava que a lógica e a dialética, juntas, deveriam ser entendidas como a arte do discurso. Tanto a sua abordagem metafísica do todo e as suas partes, quanto a sua abordagem epistemológica surge a partir das inferências tópicas e de suas bases na Teoria da Predicação a partir de Aristóteles e Porfírio. Considerando apenas as inferências tópicas, o tratamento que Boécio confere às categorias aristotélicas e aos predicáveis

${ }^{31}$ BO original: (...) the parts of a genus, and these are species (...) the parts of a complete thing, that is, of a whole whose parts are the only ones properly called 'parts'. 
de Porfírio torna claras as bases lógicas estabelecidas para a argumentação que encontramos em seus escritos. A combinação de tais influências pode ser reconhecida não apenas em seu tratamento de questões lógicas mas, também, em sua aplicação do que ele considera como a correta forma de argumentação em questões de filosofia prática. O modo como Boécio compreende gênero é tornado claro através da forma argumentativa utilizada e da abordagem linguística que justifica tal forma, sendo que o que dá força à sua concepção é o modo como o conteúdo é descoberto e utilizado.

As categorias aristotélicas bem como os predicáveis de Porfírio oferecem as bases para as inferências tópicas. Uma vez que tal forma de argumentação depende da categoria predicativa pertinente ao argumento, toda a interpretação de Boécio sobre argumentos tópicos depende do que ele aceita acerca de predicados e predicáveis. Ainda que o autor afirme que sua interpretação segue apenas Aristóteles, percebe-se claramente que há outras influências em seus escritos. Dessa forma, a nomenclatura aristotélica adquire certos desenvolvimentos peculiares à interpretação boeciana. Por fim, cabe ressaltar que, de modo geral, o corpo de escritos de Boécio não oferece divisões claras entre disciplinas filosóficas e, quando o faz, estabelece alguma dependência entre elas, em particular entre as demais disciplinas filosóficas e à lógica como conditio sine qua non para elas. Uma vez que se aponte a importância dos argumentos tópicos na obra do autor, podemos encontrar interpretações metafísicas e epistemológicas, enraizadas em uma terminologia fundamentalmente aristotélica e são defendidas por Boécio no contexto de seus comentários. Os modos de cognição são, em particular, um exemplo de como os tópicos podem ser desenvolvidos para além de uma forma lógica em uma interpretação epistemológica bastante complexa.

\section{Referências}

ARLIG, Andrew. Medieval mereology. In: ZALTA, Edward N. (ed.). The Stanford Encyclopedia of Philosophy. Stanford: Center for the Study of Language and Information, 2015. Disponível em: https://plato.stanford.edu/archives/ 
fall2015/entries/mereology-medieval/. Acesso em: 29 set. 2018. https://doi. org/10.1007/978-94-024-1151-5 330-2

DE RIJK, L. M. On the chronology of Boethius' works on the logic I. Vivarium, [s. l.], v. 2, n. 1, p. 1-49, 1964. https://doi.org/10.1163/156853464X00017

DE RIJK, L. M. On the chronology of Boethius' works on the logic II. Vivarium, [s. l.], v. 2, n. 1, p. 125-162, 1964. https://doi.org/10.1163/156853464x00053

BOÉCIO. De topicis differentiis. In: BOÉCIO. Boethius's: de topicis differentiis. Tradução: Eleonore Stump. Ithaca: Cornell University Press, 1978. p. 14-95. https://doi.org/10.5840/schoolman19795719

BOÉCIO. In Ciceronis topica. In: BOÉCIO. Boethius's in Ciceronis topica: an annotated translation of a medieval dialectical text. Tradução: Eleonore Stump. Ithaca: Cornell University Press, 1988. https://doi.org/10.7591/9781501722240

BURLEY, W. From the beginning of his treatise on the kinds of supposition (De suppositionibus). Tradução: Paul Vincent Spade. [S. l.: s. n.], 1995. Disponível em: https://pvspade.com/Logic/docs/burley.pdf. Acesso em: 5 out. 2018.

LECHTAHLER, Manuel; LIGHTFIELD, Ceth. Mereological composition and plural quantifier semantics. Philosophia, [s. l.], v. 46, n. 4, p. 943-958, Dec. 2018. https://doi.org/10.1007/s11406-018-9961-1

LIEBESCHÜTZ, H. Boethius and the legacy of antiquity. In: ARMSTRONG, A. H. (ed.). The Cambridge history of later Greek and early medieval philosophy. Cambridge: Cambridge University Press, 1967. p. 538-564. https://doi. org/10.1017/chol9780521040549.036

MARENBON, John. Boethius. New York: Oxford University Press, 2003.

NUNES, Rhamon de Oliveira. Problemas de mereologia: o que é um todo? Revista do Seminário dos Alunos do PPGLM/UFRJ, Rio de Janeiro, v. 5, n. 1, p.145-155, 2014. https://doi.org/10.17771/pucrio.acad.29491

PORFÍRIO. Isagoge: introdução às Categorias de Aristotéles. Tradução: Bento Silva Santos. São Paulo: Attar, 2002.

SPADE, Paul Vincent. History of the problem of universals in the middle ages: notes and texts. [S. l.: s. n.], 1995. Disponível em: https://pvspade.com/Logic/ docs/univers.pdf. Acesso em: 29 set. 2018.

STUMP, Eleonore. Between Aristotle and Boethius. In: BOÉCIO. Boethius's: de topicis differentiis. Tradução: Eleonore Stump. Ithaca: Cornell University Press, 1978. p. 203-214. https://doi.org/10.5840/schoolman19795719 
STUMP, Eleonore. Dialectic and Boethius's de topicis differentiis. In: BOÉCIO. Boethius's: de topicis differentiis. Tradução: Eleonore Stump. Ithaca: Cornell University Press, 1978. p. 179-204. https://doi.org/10.5840/schoolman19795719 STUMP, Eleonore. Differentia. In: BOÉCIO. Boethius's: de topicis differentiis. Tradução: Eleonore Stump. Ithaca: Cornell University Press, 1978. p. 248-261. https://doi.org/10.5840/schoolman19795719

STUMP, Eleonore. Differentia and the Porphyrian Tree. In: BOÉCIO. Boethius's: de topicis differentiis. Tradução: Eleonore Stump. Ithaca: Cornell University Press, 1978. p. 237-247. https://doi.org/10.5840/schoolman19795719

SUTO, Taki. Boethius on mind, grammar and logic: a study of Boethius' commentaries on Peri Hermeneias. Boston: Brill, 2012. (Philosophia Antiqua, v. 127). https://doi.org/10.1080/01445340.2013.777502

VARZI, A. Mereology. In: ZALTA, Edward N. (ed.). The Stanford Encyclopedia of Philosophy. Stanford: Center for the Study of Language and Information, 2016. Disponível em: https://plato.stanford.edu/entries/mereology. Acesso em: 29 set. 2018. https://doi.org/10.1108/rr-06-2015-0155

ZINGANO, Marco. As categorias de Aristóteles e a doutrina dos traços do ser. doispontos, Curitiba, v. 10, n. 2, p. 225-254, 2013. https://doi.org/10.5380/ dp.v10i2.32185 